\title{
A Mini-Review: Needleless Electrospinning of Nanofibers for Pharmaceutical and Biomedical Applications
}

\author{
Ioannis Partheniadis ${ }^{1}\left(\mathbb{D}\right.$, Ioannis Nikolakakis ${ }^{1}$ D, Ivo Laidmäe ${ }^{2}$ (D) and Jyrki Heinämäki ${ }^{2, *(D)}$ \\ 1 Department of Pharmaceutical Technology, School of Pharmacy, Faculty of Health Sciences, \\ Aristotle University of Thessaloniki, 54124 Thessaloniki, Greece; ioanpart@pharm.auth.gr (I.P.); \\ yannikos@pharm.auth.gr (I.N.) \\ 2 Institute of Pharmacy, Faculty of Medicine, University of Tartu, 50411 Tartu, Estonia; ivo.laidmae@ut.ee \\ * Correspondence: jyrki.heinamaki@ut.ee; Tel.: +372-7375281
}

Received: 30 April 2020; Accepted: 4 June 2020; Published: 6 June 2020

check for updates

\begin{abstract}
Electrospinning (ES) is a convenient and versatile method for the fabrication of nanofibers and has been utilized in many fields including pharmaceutical and biomedical applications. Conventional ES uses a needle spinneret for the generation of nanofibers and is associated with many limitations and drawbacks (i.e., needle clogging, limited production capacity, and low yield). Needleless electrospinning (NLES) has been proposed to overcome these problems. Within the last two decades (2004-2020), many research articles have been published reporting the use of NLES for the fabrication of polymeric nanofibers intended for drug delivery and biomedical tissue engineering applications. The objective of the present mini-review article is to elucidate the potential of NLES for designing such novel nanofibrous drug delivery systems and tissue engineering constructs. This paper also gives an overview of the key NLES approaches, including the most recently introduced NLES method: ultrasound-enhanced electrospinning (USES). The technologies underlying NLES systems and an evaluation of electrospun nanofibers are presented. Even though NLES is a promising approach for the industrial production of nanofibers, it is a multivariate process, and more research work is needed to elucidate its full potential and limitations.
\end{abstract}

Keywords: needleless electrospinning; nanofibers; drug delivery; tissue engineering; ultrasoundenhanced electrospinning; process limitations; alternatives

\section{Introduction}

Nanofiber technology involves the manufacturing and processing of fibers with nanoscale dimensions; the properties of such fibers are greatly dependent on their size (diameter). Nanofibers exhibit unique structural, chemical and mechanical properties such as high specific area, porosity and significant tensile strength and are therefore used in a range of applications [1].

Electrospinning (ES) is the most common method used in the fabrication of nanofibers and has found uses in both scientific research work and industrial applications [2,3]. Although ES is a simple and versatile process, some challenges associated with its low production rate and the utilization of needles as spinnerets have limited its full potential in fabricating nanofibers [3]. In recent years, some progress has been made to increase the production rate of ES by exploiting multi-needle spinnerets [4]. However, multi-needle spinnerets also present challenges and do not resolve the problem of needle clogging [1,3]. For this reason, needleless electrospinning (NLES) systems have been developed to increase nanofiber production rates and overcome the needle-associated challenges of the conventional ES process [5].

The present mini-review article was conducted by using the Scopus ${ }^{\circledR}$ (Elsevier) and the PubMed $^{\circledR}$ (NLM: United States National Library of Medicine) databases. Its aim was to elucidate the 
potential of NLES in the fabrication of nanofibers for pharmaceutical and biomedical applications. NLES technologies are reviewed in an attempt to provide, for the first time, a systematic overview of the features of NLES. Novel NLES approaches such as ultrasound-enhanced electrospinning (USES) are also discussed.

\subsection{Nanofibers}

A fiber is a substrate of natural or synthetic origin that is significantly longer than it is wide (a length/diameter L/D ratio of more than 1:200). Nanofibers are solid-state linear nanomaterials with a diameter below $100 \mathrm{~nm}$, though from the aspect of industry and engineering, submicron diameter fibers are often called nanofibers [1]. Nanofibers are expected to exhibit significantly improved properties due to the characteristics associated with their small size, large specific surface area, high number of tiny void spaces (fibrous mesh), significant mechanical strength and flexibility in functionalization. They are used in a range of applications, mainly due to their extremely large surface area to volume ratio. The high number of small void spaces combined with a void space size distribution in the micro/nano range and their light weight and flexibility also play a key role in the range of their applications [6]. The aforementioned unique characteristics of nanofibers make them suitable candidates for pharmaceutical and biomedical applications. They can be used e.g., in water and air filtration systems, membranes and environmental science as well as for manufacturing protective clothing [7].

\subsection{Classification of Nanofibers}

Fibers are mainly categorized based on their length and in particular their L/D ratio. On this basis, nanofibers are categorized as continuous or discontinuous (short) fibers, where continuous nanofibers have an L/D ratio value above 200 [8]. Moreover, nanofibers can be categorized based on the organization of their collections. A collection of nanofibers is usually referred to as a mat or a mesh. A mesh of nanofibers can be categorized as either a woven or non-woven mesh based on the arrangement of the fibers in the mesh. A woven mesh consists of fibers orientated in patterns of high regularity and a non-woven mesh is composed of continuous layers of randomly aligned nanofibers with a large pore size, usually comparable to the diameter of the fibers [3,9]. Schematic illustrations of the two types of fiber mesh are presented in Figure 1.

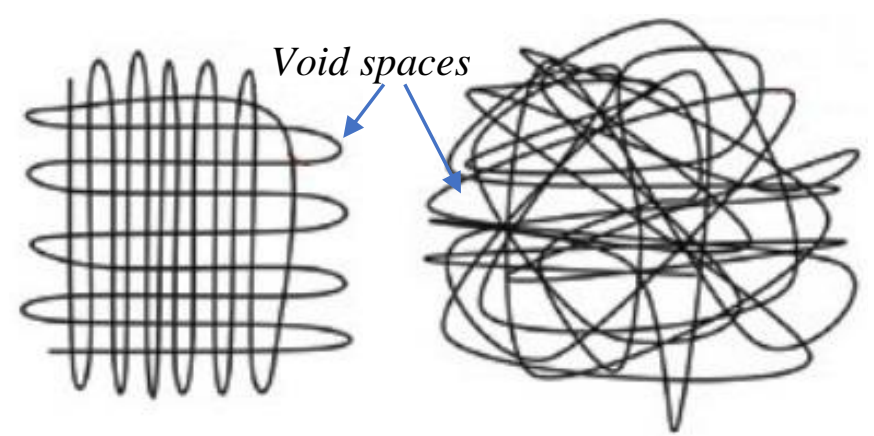

(a)

(b)

Figure 1. Schematic illustrations of (a) a woven and (b) a non-woven fiber mesh. Adapted with permission (CC BY 4.0) from [3].

\subsection{Characterization of Nanofibers}

The characterisation of nanofibers is considered from three perspectives: (i) physicochemical characterisation, (ii) mechanical properties and (iii) bioactivity and interactions. The physicochemical characterisation of nanofibers involves the evaluation of the fiber size (diameter and diameter distribution) and the structure of the mat (orientation/alignment/arrangement) by scanning electron microscopy (SEM), transmission electron microscopy (TEM), field emission scanning electron 
microscopy (FESEM) and atomic force microscopy (AFM) [10]. The crystallinity of the fibers and their surface properties (i.e., wettability) are also part of the physicochemical characterisation and can be examined using X-ray diffraction (XRD) and contact angle measurements, respectively.

The mechanical characterisation of nanofibers is usually carried out with instruments such as a texture analyser and an optical tensiometer. The properties of the nanofibers measured as part of their mechanical characterisation include: the tensile strength, elongation at break, toughness, stiffness and Young's modulus [11]. The mechanical properties of nanofibers are influenced by the polymer type and concentration, process parameters and process conditions. For example, the concentration of the polymer and its molecular weight $(\mathrm{Mw})$ can influence the solution viscosity. The solution viscosity can further affect the diameter of the fibers which is directly associated to their mechanical properties [12]. The mechanical properties also depend on the fiber microstructure, the void spaces (porosity) in the fibrous mat and their alignment [13].

The interactions of nanofibers and general chemical properties (such as molecular structure, intermolecular and intramolecular interactions) are evaluated by spectroscopic techniques: Fourier-transform infrared (FTIR) spectroscopy, Raman spectroscopy and nuclear magnetic resonance (NMR) spectroscopy. The crystalline state can be investigated by means of XRD, and the thermal behaviour and phenomena by using differential scanning calorimetry (DSC).

Other characterisation methods include e.g., the quantification of the active pharmaceutical ingredient (API), the studies of the release mechanisms of the API from the nanofibers and stability studies. UV spectrophotometry or high-performance liquid chromatography (HPLC) coupled with different sensors, liquid chromatography-mass spectroscopy (LC-MS) and other analytical methods can be used for these purposes.

\section{Conventional Electrospinning of Nanofibers}

\subsection{Fundamentals and Equipment}

Nanofibers can be prepared from a variety of materials, but in the pharmaceutical and biomedical context they typically comprise a polymeric carrier loaded with a drug. There are reports of various techniques for fabricating pharmaceutical nanofibers: (i) drawing, (ii) phase separation, (iii) melt-blown technology, (iv) template synthesis, (v) forcespinning, (vi) freeze-drying and (vii) electrospinning (ES). Of these methods, ES is the most commonly used and preferred method since it is an easy, reliable and versatile production technology with potential to scale-up [14]. In this method, electrical forces are utilised to fabricate nanofibers [2].

ES can be applied to a range of both natural and synthetic materials (e.g., polymers), from liquids (such as melts), and the solutions or suspensions of small molecules (e.g., active pharmaceutical ingredients-APIs, biological materials, cells or bacteria) [15]. For the ES of polymers or co-systems of polymers and APIs, the solution approach is more common. A typical experimental set-up of a conventional ES process is presented in Figure 2.

A typical experimental set-up of a conventional ES process consists of four main components: a high-voltage power supply, a syringe pump, a syringe fitted with a metal needle (the spinneret) and a grounded collector. A high-voltage power supply (typically between 5 and $25 \mathrm{kV}$ ) is connected to both the spinneret and the collector, where the spinneret is usually charged positively or negatively and the collector is either grounded or oppositely charged to the spinneret [16]. The syringe is filled with a feed solution, which is subsequently extruded through the spinneret at a constant flow rate and controlled by a syringe pump. The high-voltage electrical field is essential for an ES process. If a solution is ejected from a syringe without a voltage supply, it will exit the syringe in the form of spherical droplets to minimise its surface tension [3]. 


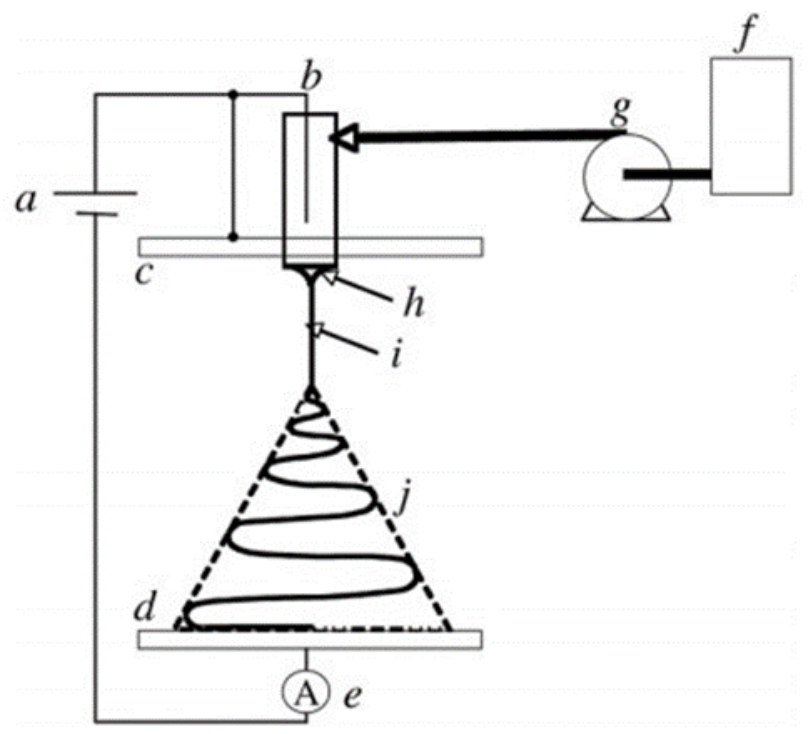

Figure 2. Schematic illustration of an experimental set up of a conventional electrospinning process: (a) high-voltage supply, (b) charging device of the spinneret, (c) high-potential electrode, (d) grounded collector, (e) current measurement device, (f) working solution reservoir, (g) flow rate control of the syringe pump, (h) Taylor's cone, (i) thinning jet and (j) instability region. Reprinted with permission from [16].

As the feed solution begins to extrude through the syringe, in the application of a high-voltage electrical field, the formation of a cone known as Taylor's cone, is observed. At the tip of the cone, the polymer solution emits a jet which rapidly stretches, becoming elongated and thinner (jet thinning). In ES, the free charges carried by the feed solution interact with the applied electric field, and a tensile force generated due to the potential difference between the charged solution in the spinneret and the grounded collector induces fiber jetting [17]. The jet travels away from the spinneret towards the collector, while at the same time the solvent evaporates. By the time the jet reaches the grounded collector, it is discharged and the solvent has evaporated, leaving behind dry fibrous solid products. Typically, the distance between the syringe and the collector is ca. $10-20 \mathrm{~cm}$, or even higher [18].

\subsection{Parameters Affecting ES Process}

The parameters affecting the ES process have been discussed in a number of review articles $[3,19,20]$ and numerous studies have been performed to elucidate the ways in which the ES process is affected by material, processing and environmental parameters.

The properties of a polymer solution have an important influence on the fabrication of nanofibers using an ES method. Properties such as the viscosity, surface tension, dielectric constant, conductivity, concentration and molecular weight of the polymer as well as the volatility of the solvent play a major role, as they can affect the size, morphology and mechanical properties of electrospun nanofibers $[12,19,21]$. Moreover, processing parameters such as the applied electrical field, the flow rate of the feed solution, the diameter of the spinneret inner orifice, the distance between the spinneret and the collector (operating parameters) and the design of an experimental set-up affect the ES [12,22]. Environmental parameters, such as temperature and relative humidity could also affect the process and should not be underestimated. In addition to temperature and humidity, the air flow and ventilation of the laboratory could affect the ES process, including the stability of the Taylor cone, the characteristics of the polymer jet and the rate of solvent evaporation. This could result in significant changes in the final properties of nanofibers [23]. For this reason, ES is usually performed in an electrically insulated enclosed space.

The same solution, processing and ambient parameters that affect conventional ES can also affect needleless electrospinning (NLES) for the fabrication of nanofibers. 


\subsection{Challenges to Conventional ES}

ES is a widely applied technique in the fabrication of nanofibers, although there are challenges that need to be overcome. For instance, the use of volatile solvents in the polymeric solution results in health and safety issues which also limit the scalability of the process at an industrial level [3]. The main challenges that are associated with the the ES process and limit its scalability are listed below:

i. $\quad$ ES is a very slow and time-consuming process. A standard laboratory experimental set up works at a few $\mathrm{mL} / \mathrm{h}$ (usually $0.5-1 \mathrm{~mL} / \mathrm{h}$, or even higher), which means that when a solution with $8 \% w / v$ polymer is spun, at 10 working hours, the maximum amount of nanofibers that can be produced is $800 \mathrm{mg}$ (assuming the 100\% yield of the process). In actual laboratory conditions, the production rate of the nanofibers is extremely low, varying from 0.01 to $0.1 \mathrm{~g} / \mathrm{h}$. To tackle this issue, some modifications in the ES set-up have been suggested using multi-needle spinnerets $[14,20]$.

ii. Multi-needle spinnerets, however, also present challenges. The applied electric field at an individual needle will be affected by the electric fields and the jets of other needles which are close by. The interreference between the jets will affect the homogeneity of the final products [24].

iii. The downwards spinning of the jets has the disadvantage of forming droplets at the tip of the needle, which can fall onto the collector, thus hindering the formation of a nanofiber mat [25].

iv. Needle clogging may occur due to the narrow inner diameter orifice of the spinnerets, which are used to reduce the fiber's diameter and prevent the formation of beads in the final products [26].

Many studies have made attempts to overcome the limitations of conventional ES and expand its capability by combining ES with other technologies. Recently, Pawłowska et al. (2020) designed the novel approach of light-assisted co-axial ES for the preparation of core-shell fully cross-linked p(NIPAAm-co-NIPMAAm) hydrogel-based nanofibers for the thermally induced drug delivery of rhodamine B [27]. However, in order to overcome the aforementioned challenges and disadvantages of a needle-type spinneret ES process, the implementation of a NLES approach was proposed.

\section{Needleless Electrospinning}

\subsection{Overview}

Needleless electrospinning (NLES) is the process of fabricating nanofibers by electrospinning a polymeric solution directly from an open liquid surface. The first experimental set up of a NLES process was developed by Simm et al. in 1979 using an annular electrode as a spinneret [28]. However, NLES began to attract the interest of researchers only after 2004, when Yarin and Zussman utilised a magnetic field to prompt spike formations on the surface of a solution for the initiation of an ES process [29]. A year later, Jirsak et al. (2005) patented the first NLES set-up, which was later commercialised by Elmarco s.r.o. (Liberec, Czech Republic) with the brand name "Nanospider" [30]. Their patent involved using a rotary cylinder as a spinneret. This spinneret was partially immersed and rotating in a polymeric solution, allowing the formation of a thin layer of solution on its surface and thus the formation of spikes, which, after the application of an electrical field, initiated ES. Since then, many proposals for NLES set-ups were reported, including the employment of air bubbles [31], a conical wire assisted by the act of gravity [32], a metal plate [33], a splashing spinneret [34], a rotary cone [35], a bowel edge [36] and more recently a toothed wheel [37], a linear flume [4] and a shear-aided spinneret [38] to initiate the ES process for the fabrication of nanofibers.

The polymeric jet initiation in NLES is a self-organised process occurring on a free liquid surface and it is not prompted by the capillary forces, which is the case for needle-like spinneret ES [39]. Thus, NLES is a hard-to-control process. Spinnerets therefore play a major role in the performance of the NLES process and finally fiber quality, as demonstrated by Niu et al. (2009) [40]. The spinnerets used in NLES were classified in two main categories: (i) rotating and (ii) stationary. A second classification was based on the direction in which the jets travel from the spinneret to the collector. Therefore, three further categories can be defined: (i) downwards, (ii) upwards and (iii) sideways ES. 


\subsection{Rotating Spinnerets in NLES}

NLES is based on the use of an external agitating force to concentrate the electrical field on a free liquid surface up to the intensity level needed to initiate a Taylor cone. In the case of rotating spinnerets, rotation is used to feed the initiated Taylor cones with polymeric solution to keep the NLES process uninterrupted and continuous. The Taylor cones are usually generated away from the polymeric solution at certain positions, where the intensity of the electrical field is appropriate to maintain the ES process. Most of the experimental set-ups in NLES utilising rotating spinnerets were based on the technology of Nanospider ${ }^{\circledR}$ (Elmarco s.r.o.) [30]. The direction of ES is usually upwards in order to prevent the spinning solution from dropping onto the fabricated mat. The NLES set-ups used previously for the fabrication of nanofibers for pharmaceutical and biomedical applications are: (i) cylinder (Nanospider ${ }^{\circledR}$ ), (ii) disc, (iii) ball and (iv) wire/rod ES systems. Figure 3 shows the schematic diagram of the reported types of rotating NLES spinnerets.

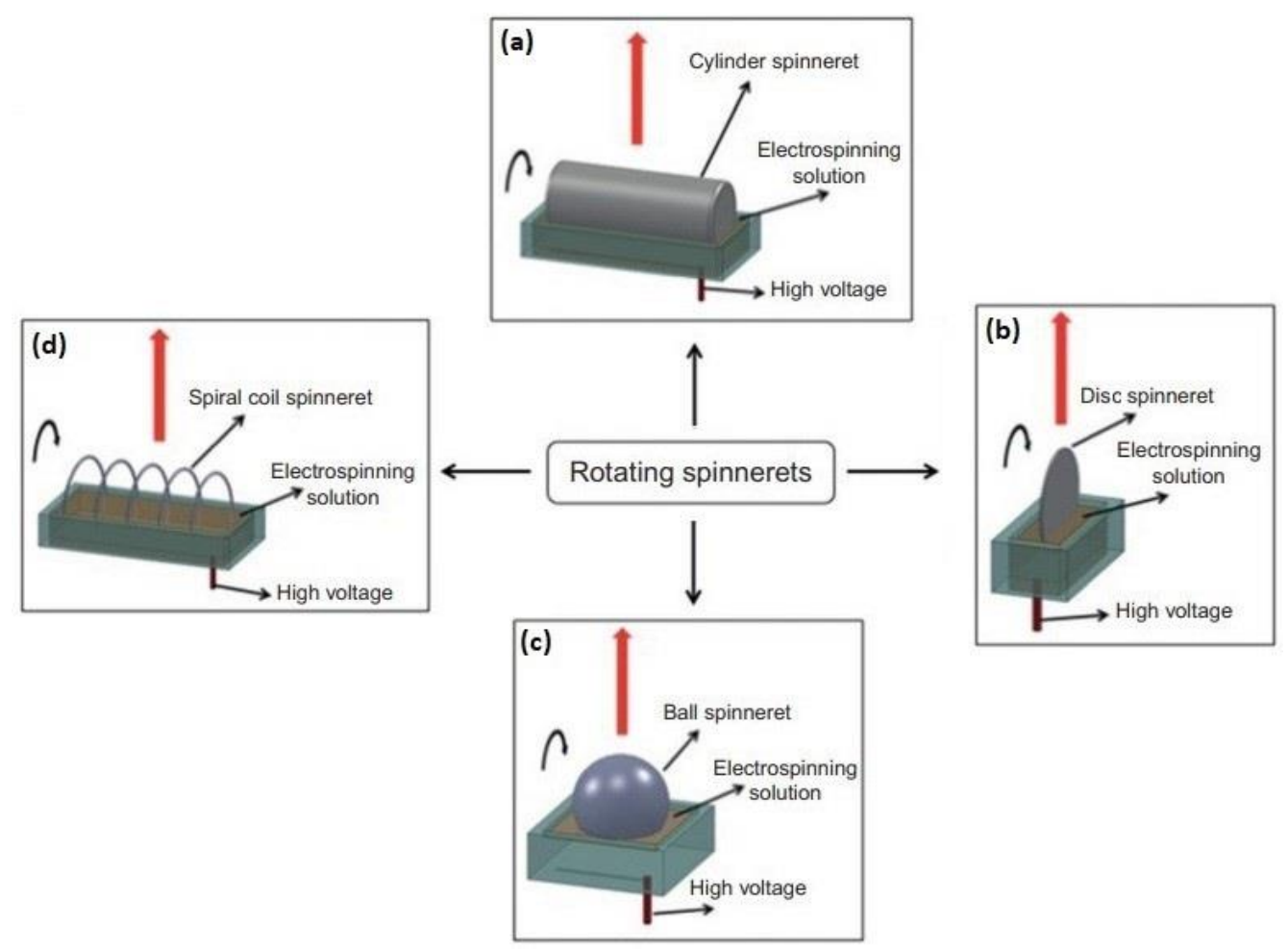

Figure 3. Schematic diagram depicting the rotating spinnerets: (a) cylinder spinneret, (b) disc spinneret, (c) ball spinneret and (d) wire/coil spinneret in needleless electrospinning (electrospinning direction along the red arrow). Adapted with permission (CC BY 3.0) from [39].

The cylinder spinneret used in NLES shown in Figure 3a refers to the Nanospider ${ }^{\circledR}$ technology, which was patented by Jisrak et al. [30] and commercialised by Elmarco s.r.o. This technology offers many advantages, the most important of which is that the Taylor cones are initiated spontaneously at optimal positions. The fabrication of nanofibers utilising Nanospider ${ }^{\circledR}$ technology relies on the four steps described below:

i. The metal roller spinneret is partially immersed in the polymeric solution. As it rotates, a thin layer of solution is formed on its surface.

ii. The rotation of the spinneret causes agitations of the solution layer and thus the formation of conical spikes.

iii. When a high electrical field is applied, the conical spike deforms to a Taylor cone.

iv. Finally, polymeric jets are stretched out of the Taylor cones' tips and the fabricated nanofibers are collected. 
Nanospider ${ }^{\circledR}$ technology is widely applied for the fabrication of nanofibers aimed at pharmaceutical and biomedical applications, as we will discuss later in Section 3 of the present review. As Yener and Jisrak (2012) reported, this technology leads to thicker electrospun nanofibers and requires a higher voltage supply compared with conventional needle ES [41]. The electric field distribution in a cylinder spinneret is unevenly distributed, with its intensity being higher at the edges of the spinneret and lower in the middle [40].

The same principles also apply to the other NLES rotating spinnerets presented in Figure 3. Disc spinnerets (Figure 3b) generate finer fibers with better diameter uniformity since the electric field is more uniformly distributed in the spinneret [40,42]. In ball ES (Figure 3c), the electric field is evenly distributed on the top-half of the spinneret and has been found to result in coarser nanofibers with a lower yield compared with cylinder and disc spinnerets [43]. Spiral wire spinnerets (Figure 3d) have been found to generate more uniform and thinner fibers than the conventional needle ES process and usually require a higher voltage supply than conventional ES set-ups [44].

\subsection{Stationary Spinnerets in NLES}

The stationary spinnerets utilised in NLES generate Taylor cones by exploiting an external force, such as a magnetic force, high pressure gas flow, gravity or more recently, an acoustic radiation force generated by an ultrasound transducer $[26,29,31]$. Again, as in the case of the rotating spinnerets, the direction of ES is usually upwards to avoid defects in the nanofibrous mat by dropping solution onto it. Figure 4 presents the stationary spinnerets of the NLES systems reported in the state of the art literature.

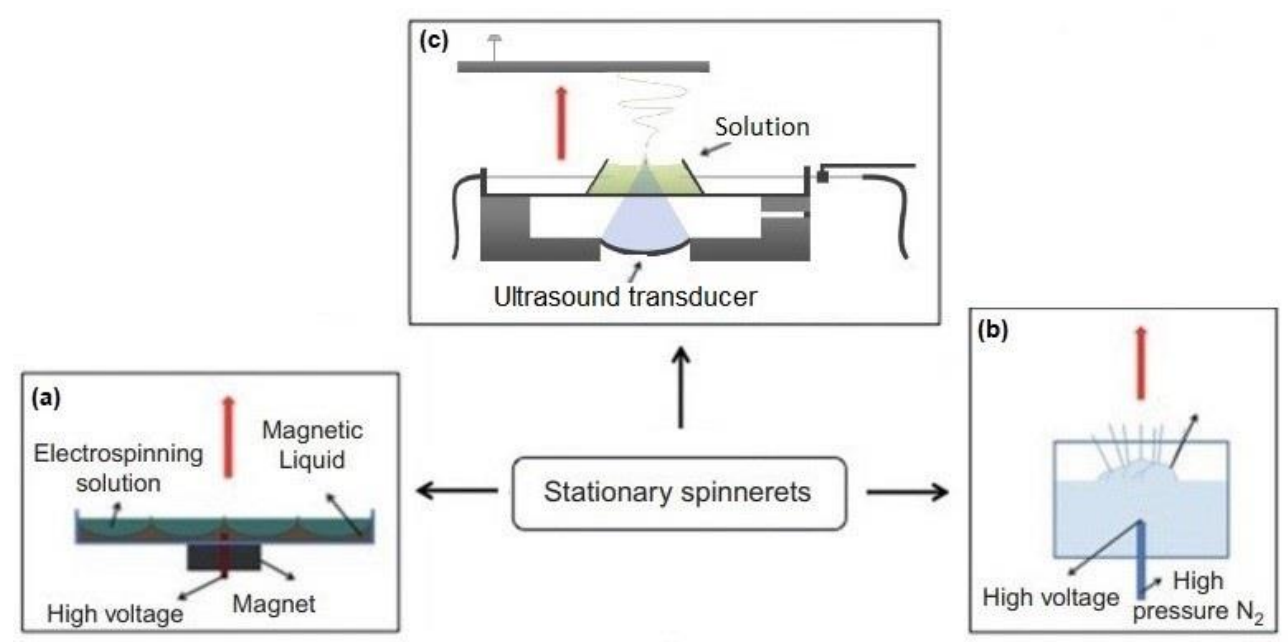

Figure 4. Schematic diagram depicting the stationary spinnerets: (a) ferromagnetic liquid, (b) bubble and (c) ultrasound-enhanced electrospinning, USES (electrospinning direction along the red arrow). Adapted with permission (CC BY 3.0) from [39,45].

The ferromagnetic liquid electrospinning process was proposed as the first attempt to use stationary spinnerets for NLES by Yarin and Zussman in 2004 [37]. This approach utilises a system of two liquids: (i) a sublayer of a ferromagnetic suspension and (ii) an upper layer of polymeric solution. The system is subjected to a magnetic field provided by a permanent magnet or coil, resulting in the perturbation of the upper layer polymeric solution by the spikes of the ferromagnetic suspension as shown in Figure 4a. By applying an electric field to the above described system, the perturbations become generating sites for the ES process. This process is reported to have a higher production yield than conventional ES [37].

In Figure $4 \mathrm{~b}$ an experimental set-up of bubble electrospinning is described. In bubble electrospinning, the jets start to stretch out from the bubbles instead of the tips of Taylor cones [31]. The principle of this method was to produce bubbles on the free surface of a polymeric solution by 
passing pressurised air or nitrogen $\left(\mathrm{N}_{2}\right)$ into the solution, and as the bubbles are burst on the surface of the solution, multiple jets are stretched out and ES is initiated.

More recently, in 2016, Laidmäe et al. patented a novel method for the fabrication of nanofibers by utilising ultrasound-enhanced electrospinning (USES) (Figure 4c) [46]. Since USES is a novel technology for the fabrication of nanofibers and has not been described previously, it was deemed appropriate to provide a description of this method separately in the following section.

\subsection{Ultrasound-Enhanced Electrospinning}

Ultrasound-enhanced electrospinning (USES) is a novel NLES approach for the fabrication of nanofibers. This technology was patented in 2016 by Laidmäe et al. [46] as a continuous orifice-less technique that employs high-intensity focused ultrasound for the fabrication of nanofibers from a free surface polymeric solution. In Figure 5, the USES method and setup are presented.
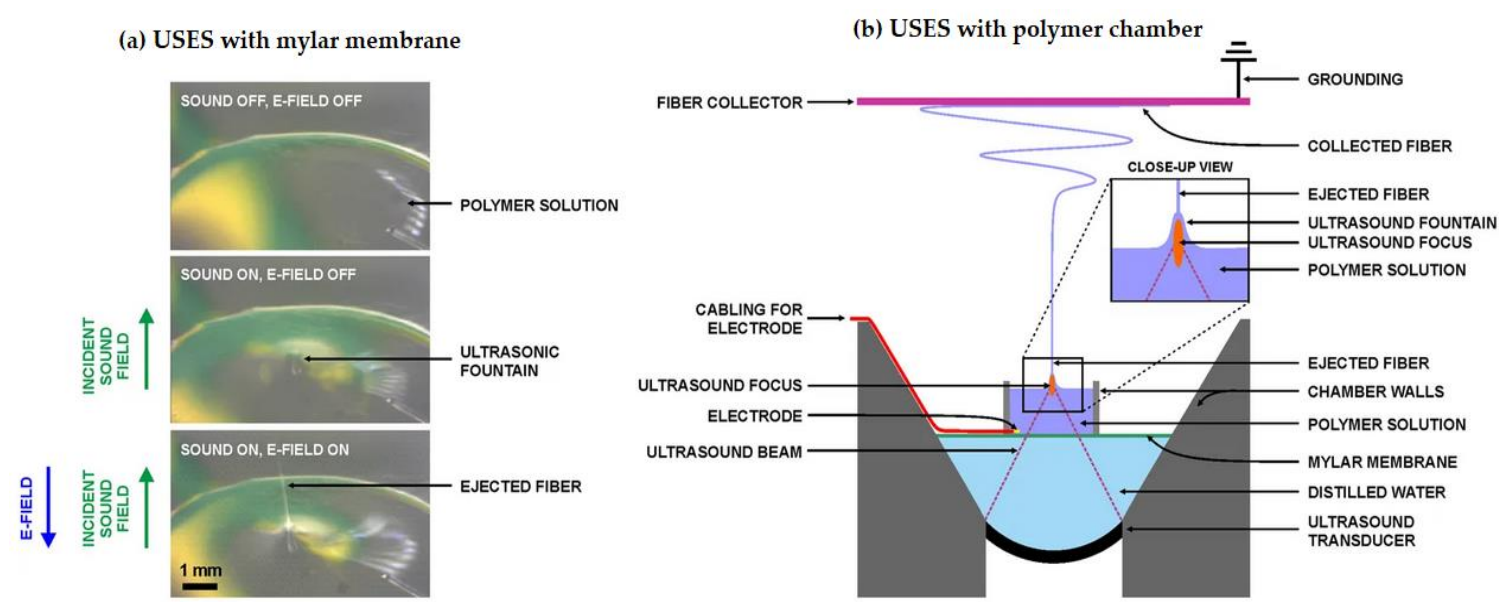

Figure 5. (a) An ultrasound-enhanced electrospinning (USES) method with a mylar membrane and (b) a USES system with a polymer chamber. Reprinted with permission (CC BY 3.0) from [26].

Nieminen et al. (2018) described a USES system and studied for the first time the fabrication of nanofibers via USES using a polymeric solution of polyethylene oxide (PEO) in water [26]. As can be seen in Figure 5a, the application of a high-intensity ultrasound generated an ultrasonic fountain when a droplet of the polymeric solution was placed on a mylar membrane (an acoustically conducting but electrically isolating membrane). After the application of an electrical field, a liquid jet was ejected from the top of the ultrasonic fountain [26]. In Figure 5b, a USES system is presented showing the polymer chamber. The system consists mainly of a mylar membrane and an ultrasound transducer as well as distilled water in the space between them, which is used to focus the acoustic beam at the polymer-air interface. The polymer solution is placed in a chamber which allows direct contact of the solution with the mylar membrane. An electrode is then used to negatively charge the polymeric solution and a grounded (or positively charged) target is placed above the ultrasound fountain in order to initiate the ES process [26].

Nieminen et al. (2018) reported the modification of the topography of the USES electrospun nanofibers in a non-chemical manner [26]. The authors also reported some phenomena that occured in the vicinity of the ultrasound fountain and could be associated with the ability to control nanofibers properties via USES. These are: (i) the ultrasound fountain in conjunction with the applied electrical field, (ii) the capillary waves on the surface of the polymeric solution generated by the ultrasounds, (iii) cavitation, (iv) acoustic streaming and (v) thermal effects [26].

More recently, Hakkarainen et al. (2019) compared traditional ES (TES) and USES in the fabrication of nanofibrous drug delivery systems [45]. They reported that TES produced thinner and somewhat more uniform-by-size nanofibers than USES (77 $\pm 21 \mathrm{~nm}$ for TES compared to $402 \pm 127 \mathrm{~nm}$ and 
$555 \pm 265 \mathrm{~nm}$ for USES) and assigned this difference to the fact that USES is a multivariate process involving more critical parameters than TES. USES generated nanofibers that were also beadless. Moreover, they reported the modulation of fiber diameter by controlling the cycles per ultrasound pulse. They examined the fabricated nanofibers by PXRD, DSC and FTIR spectroscopy and found that the USES nanofibers were amorphous, whereas TES nanofibers were less prone to amorphicity. The authors concluded that USES provided a promising alternative for the aqueous-based fabrication of nanofibrous drug delivery systems, although further research is needed to discover all the potential strengths and limitations of this novel NLES method.

\section{Pharmaceutical and Biomedical Applications of NLES}

The state of the art studies on NLES for the fabrication of nanofibers aimed at biomedical or pharmaceutical applications are summarised in Table 1 . Table 1 shows that the most experimental NLES set-ups are based on rotating spinnerets rather than stationary ones (namely $82.5 \%$ of the total studies presented) and also the upwards direction of ES is preferred (92.6\% of the total studies presented). Moreover, it can be seen that the Nanospider ${ }^{\circledR}$ (Elmarco s.r.o., Liberec, Czech Republic) technology for NLES is the most utilised ( $48.1 \%$ of the total studies and $59.1 \%$ of the studies utilising rotating spinnerets).

\subsection{NLES Technologies Using Rotating Spinnerets}

NLES is a method of fabrication of nanofibers proposed in 1979 by Simm et al. [28], although the first implementation of NLES aimed at potential pharmaceutical applications was investigated by Sirc et al. (2012) [47]. In their work, they fabricated polyvinyl alcohol (PVA) and polyurethane (PUR) multi-layered electrospun nanofibers utilising Nanospider ${ }^{\circledR}$ (Elmarco s.r.o.) technology. The multi-layered sandwich nanofibrous structures consisted of three layers of PUR/PVA/PUR and the mid-layer also consisted of the drug (gentamicin). They reported controlled a release of gentamicin from the nanofibrous structures and also retained the antimicrobial activity against S. aureus and P. aeruginosa.

Ai-Tang et al. (2013) [48] used a Nanospider ${ }^{\circledR}$ experimental set-up for the fabrication of cellulose acetate (CA)- and PEO-based nanofibers for the encapsulation of natural seed oil (NSO). They successfully prepared ultrafine fibers from a blend solution of CA and PEO, and the average diameter of the fibers was $1.5 \mu \mathrm{m}$. They reported that the fibers containing the encapsulated NSO presented beads on their microstructure due to the large droplets of NSO $(32.1 \mu \mathrm{m})$. The authors evaluated the produced fibers for their antifungal activity and found them to be effective against A. flavus and A. alternata. Therefore, the produced electrospun fibers could be used as antifungal materials for perishable corps and furthermore, their results showed that they could also have potential application as antifungal films.

Huang et al. (2013) [49] studied the fabrication of cellulose acetate butyrate (CAB) nanofibers by disc-ES and the conventional ES process. The disc-ES set-up consisted of a rotary disc spinneret and an upwards rotary drum as the collector. They reported the biocompatibility of the electrospun nanofibers with fibroblasts and Schwann cells and enhanced cellular growth shown by the disc-electrospun nanofibers. Using the same experimental set-up of the disc-ES, Li et al. (2014) [50] investigated the fabrication of polycaprolactone (PCL) scaffolds with 3D architecture and a porous surface by disc-ES. They reported the enhancement of cell attachment and the proliferation of fibroblasts in a 7-day study, compared with solid fibers, solvent cast and tricalcium phosphate. Another research group, led again by Li (2016) [51], fabricated multiscale PCL/gelatine (PCL/GT) nanofibrous and microfibrous scaffolds via disc-ES. They compared the PCL/GT scaffolds with acetic acid-assisted PCL/GT-A scaffolds and found that PCL/GT scaffolds had larger pores and enhanced cell infiltration, while PCL/GT-A scaffolds inhibited cells on their surface. They concluded that PCL/GT scaffolds of multiscale structure could be used in tissue engineering.

Syrová et al. (2015) [52] used an experimental set-up with a rotating spinneret partially immersed in a polymeric solution and with upwards $\mathrm{ES}$ for the fabrication of $\mathrm{SiO}_{2}$ nanofibers as scaffolds for 
human bone marrow mesenchymal stem cells (hMSC). Despite the fact that their set-up is very similar to Nanospider ${ }^{\circledR}$ (Elmarco s.r.o.), there was no mention of this in their work. They successfully prepared electrospun silica nanofibers as suitable scaffolds to support the adhesion of hMSC, but they also reported a tendency to release toxic eluates during in vitro cell culture tests.

Lu et al. (2016) [53] produced gelatine (GE) nanofibers containing chitosan oligosaccharide (COS) and alginate sodium (AS) by utilising a spiral-ES experimental set-up. A helix slice rotary spinneret was partially immersed in the polymeric solution and the polymeric jets were travelling upwards to the collector. They studied the effects of the concentration of the polymeric solution, the rotation speed of the spinneret and the spinning distance on the morphology of the nanofibers. They concluded that the spiral-ES is appropriate for the mass ES of nanofibers reporting an enormously high productivity of $40-400 \mathrm{~g} / \mathrm{h}$. Furthermore, smooth and uniform nanofibers could be fabricated by the careful control of the process parameters.

Sasithorn et al. (2016) [54] studied the effect of processing parameters on the fabrication of silk fibroin nanofibers utilising the NLES process with a rotating wire as a spinneret fed by the solution. They found that increasing the concentration of the silk fibroin in the solution and the applied voltage improved the spinning ability and performance. They also performed in vitro biocompatibility tests with MG-63 osteoblasts, that revealed high biocompatibility with silk fibroin nanofibers and they concluded that their products were promising for bone-tissue engineering.

Li et al. (2019) [55] proposed an NLES technology using a rotary linear spinneret with a weir as an electrode. The spinneret is partially immersed in the polymeric solution and the ES direction upwards. They studied the influence of the solution's viscosity and electrical conductivity in the fabrication of PVA/chitosan(CS)/graphene(Gr) nanofibrous membranes by modulating the content of CS in the solution. The results showed that the hydrophilicity and morphology of the PVA/CS/Gr nanofibrous membranes were affected by the presence of CS, while the FTIR spectroscopy analysis revealed hydrogen-bonding between CS and PVA, which enhanced the thermal properties of the membranes. In another work of the same researchers [56], a methodology for the preparation of PVA/AS/Gr/Carbon nanotubes (CNTs) and nanofibrous membranes was proposed. The microstructure, conductivity and hydrophilicity of the membranes was studied and the results showed good hydrophilicity and thermal stability. In both works, the researchers concluded that the proposed membranes were promising in the field of tissue engineering.

Lukášová et al. (2019) [57] prepared nanofibrous scaffolds from PCL in combination with platelets by utilising two methods: centrifugal ES and NLES. Centrifugal ES was performed using a cyclone device as the spinneret and the ES direction was sideways. The NLES was performed by utilising Nanospider ${ }^{\circledR}$ technology. Centrifugal ES generated the 3D-structured porous nanofibrous scaffolds, while NLES yielded the 2D-structured products. The prepared scaffolds were tested for cell proliferation, metabolic activity and osteogenic differentiation using hMSCs. Centrifugal electrospun nanofibrous scaffolds showed a higher cell proliferation. The functionalisation of the scaffolds with the platelets and their culture in an osteogenic differential medium showed improved osteoinduction by the platelets in environments rich in inorganic phosphate and ascorbate. The results of the study pointed to the potential application of the electrospun nanofibrous scaffolds in bone tissue engineering.

\subsection{Commercialised NLES Apparatuses Using Rotary Spinneret}

NLES apparatuses with rotary spinnerets for the fabrication of nanofibers have been widely commercialised. The best known and the most utilised apparatus is Nanospider ${ }^{\circledR}$ by Elmarco s.r.o. (Liberec, Czech Republic) (Table 1). A number of other manufacturers are also trading NLES apparatuses based on rotary spinnerets, such as the EDEN ${ }^{\circledR}$ series by MECC Co Ltd (Fukudo, Japan) and the Ispun ${ }^{\circledR}$ series by Ucalery Co (Beijing, China). To the best of our knowledge (and based on the articles published within the past three years, 2017-2020), Nanospider ${ }^{\circledR}$ (Elmarco s.r.o.) technology is the only technology to date applied to the fabrication of nanofibers with potential biomedical and 
pharmaceutical applications. The studies that have been reported until now are presented in Table 1 but only the most important are discussed below.

Sirc et al. (2017) [58] fabricated poly(D,L-lactic acid)/poly(ethylene glycol) (PLA/PEG) nanofibers loaded with cyclosporine $A$ and studied the drug release characteristics of their system in a phosphate-buffer solution (PBS) and on concanavalin simulated spleen cells. They found biological activity in their system even after $144 \mathrm{~h}$ and concluded that the proposed system was promising for local immunosuppression in various medical applications.

Böttjer et al. (2018) [59] co-electrospun a series of biopolymers (keratin, collagen, dextran and poloxamer) with PEG or polyacrylonitrile (PAN) to achieve the water-resistance of the mats. They also tried to give water-resistant properties to the mats by photo-crosslinking PEG with pentaerythritol tetraacrylate (PETRA), but without success. In conclusion, they proposed that the increased stability of the biopolymer blend aided their successful use in medical and biotechnological applications.

Kurečič et al. (2018) [60] developed a process to prepare novel multifunctional nanofibrous materials based on cellulose acetate (CA) loaded with benzocaine (BZC) and a pH-indicator dye, bromocresol green (BCG). The results obtained in the in vitro drug release study showed the controllable and $\mathrm{pH}$-dependent release of $\mathrm{BZC}$, reaching a maximum release at $\mathrm{pH} 9.0$, which is the $\mathrm{pH}$ of an infected wound. BCG changed its colour relative to the $\mathrm{pH}$ changes, making the proposed nanofibrous mats an ideal in-situ pH-detecting system. They also tested the biocompatibility of the proposed mats with human skin fibroblast cells and confirmed their potential use in wound treatment applications.

Petrova et al. (2019) [61] prepared an electrospun bilayer material made from CS and hyaluronan (HA) by the sequential ES of a HA-PEO monolayer matrix onto a freshly formed CS-PEO monolayer matrix and tested its biocompatibility with hMSCs. They found a good biocompatibility of the bilayer scaffold with hMSCs and proposed its use for tissue engineering applications.

Recently, Klicova et al. (2020) [62] introduced novel double layered planar scaffolds by combining hydrophobic PCL nanofibers and PVA hydrogels. They tested the produced scaffolds in terms of the morphology, wettability, adhesion and the proliferation of mouse fibroblasts and found that the greatest proliferative activity was exhibited by the PCL fibers. When the scaffolds were exposed to water, the PVA layer formed a hydrogel-like structure with a shape defined by the water-stable PCL layer. They concluded that the prepared scaffolds could be useful in wound dressing or abdominal adhesion prevention. 
Table 1. Studies on needleless electrospinning (NLES) for the fabrication of nanofibers aimed at biomedical or pharmaceutical applications.

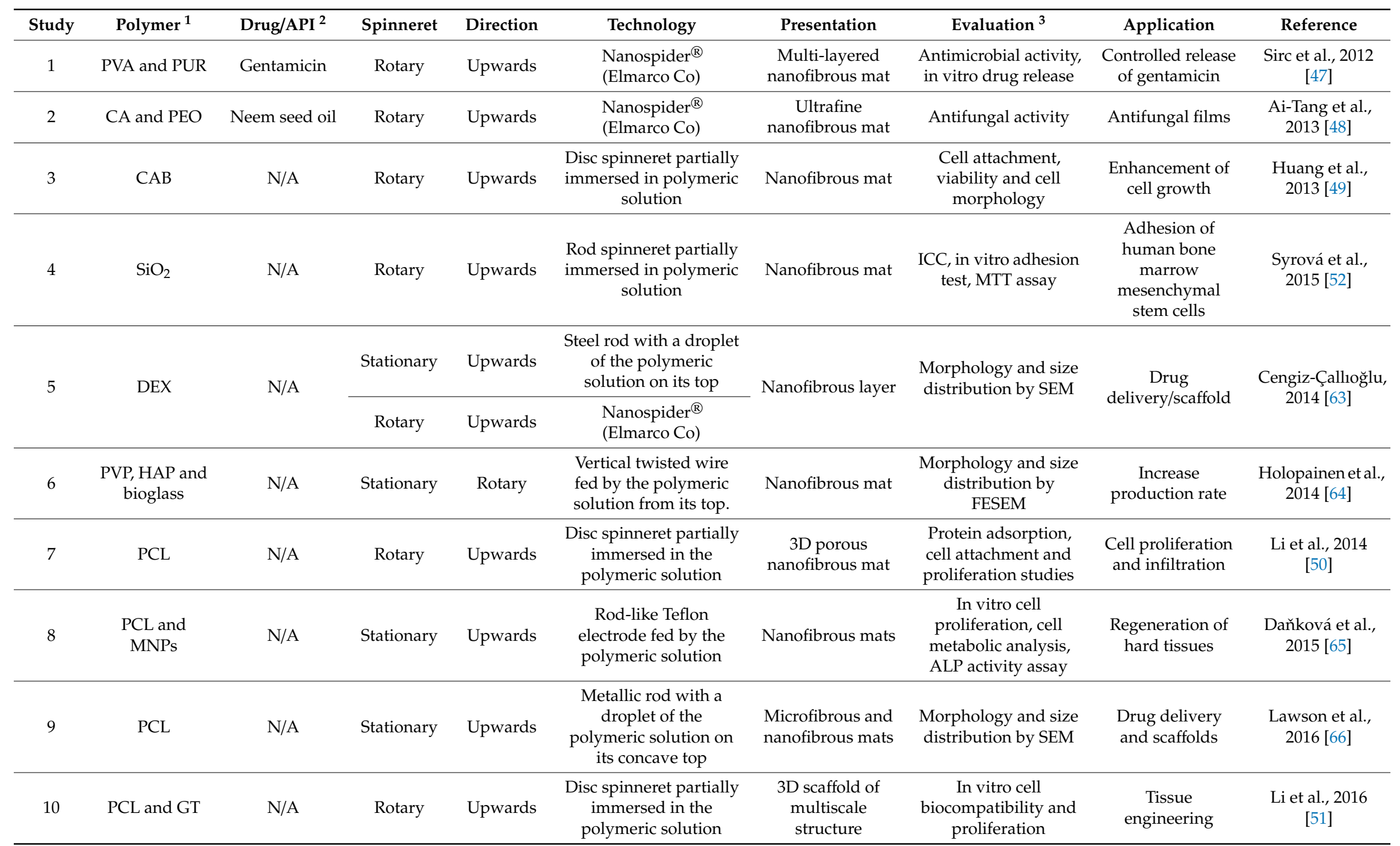


Table 1. Cont.

\begin{tabular}{|c|c|c|c|c|c|c|c|c|c|}
\hline Study & Polymer $^{1}$ & Drug/API ${ }^{2}$ & Spinneret & Direction & Technology & Presentation & Evaluation $^{3}$ & Application & Reference \\
\hline 11 & $\begin{array}{c}\text { GT, CSO and } \\
\text { AS }\end{array}$ & N/A & Rotary & Upwards & $\begin{array}{l}\text { Helix slice spinneret } \\
\text { partially immersed in } \\
\text { polymeric solution }\end{array}$ & Nanofibrous mat & $\begin{array}{l}\text { Morphological } \\
\text { characterisation }\end{array}$ & Biomedical field & $\begin{array}{c}\text { Lu et al., } 2016 \\
\text { [53] }\end{array}$ \\
\hline 13 & PLA and PEG & $\begin{array}{c}\text { Cyclosporine } \\
\text { A }\end{array}$ & Rotary & Upwards & $\begin{array}{l}\text { Nanospider }{ }^{\circledR} \\
\text { (Elmarco Co) }\end{array}$ & Nanofibrous mats & $\begin{array}{l}\text { In vitro drug release, } \\
\text { Inhibition test of IL-2 }\end{array}$ & $\begin{array}{c}\text { Local } \\
\text { immunosuppression }\end{array}$ & $\begin{array}{c}\text { Sirc et al., } 2017 \\
{[58]}\end{array}$ \\
\hline 14 & PEG and PAN & $\begin{array}{c}\text { Keratin, } \\
\text { collagen, } \\
\text { dextran and } \\
\text { poloxamer }\end{array}$ & Rotary & Upwards & $\begin{array}{l}\text { Nanospider }{ }^{\circledR} \\
\text { (Elmarco Co) }\end{array}$ & Nanofibrous mats & $\begin{array}{l}\text { Morphology by } \\
\text { CLSM }\end{array}$ & $\begin{array}{l}\text { Increase water } \\
\text { stability for } \\
\text { biotechnological } \\
\text { applications }\end{array}$ & $\begin{array}{l}\text { Böttjer et al., } \\
2018 \text { [59] }\end{array}$ \\
\hline 15 & $\mathrm{CA}$ & $\begin{array}{l}\text { Benzocaine } \\
\text { and } \\
\text { bromocresol } \\
\text { green }\end{array}$ & Rotary & Upwards & $\begin{array}{l}\text { Nanospider }{ }^{\circledR} \\
\text { (Elmarco Co) }\end{array}$ & Nanofibrous mats & $\begin{array}{l}\text { In vitro drug release, } \\
\text { halochromic } \\
\text { behaviour, } \\
\text { biocompatibility tests }\end{array}$ & Wound treatment & $\begin{array}{l}\text { Kurečič et al., } \\
2018 \text { [60] }\end{array}$ \\
\hline 16 & PLA and PEG & Paclitaxel & Rotary & Upwards & $\begin{array}{l}\text { Nanospider }{ }^{\circledR} \\
\text { (Elmarco Co) }\end{array}$ & Nanofibrous mats & $\begin{array}{c}\text { In vitro drug release, } \\
\text { swelling studies }\end{array}$ & $\begin{array}{c}\text { Localised } \\
\text { chemotherapy }\end{array}$ & $\begin{array}{l}\text { Hampejsova et al., } \\
2019 \text { [67] }\end{array}$ \\
\hline 17 & PLA and PEG & Paclitaxel & Rotary & Upwards & $\begin{array}{l}\text { Nanospider }{ }^{\circledR} \\
\text { (Elmarco Co) }\end{array}$ & $\begin{array}{l}\text { Micro-/nanofibrous } \\
\text { mats }\end{array}$ & $\begin{array}{l}\text { In vitro drug release, } \\
\text { cytotoxicity, CAM } \\
\text { assay, In vivo model } \\
\text { of local tumour } \\
\text { recurrence }\end{array}$ & $\begin{array}{c}\text { Localised } \\
\text { chemotherapy }\end{array}$ & $\begin{array}{l}\text { Hobzova et al., } \\
2019 \text { [68] }\end{array}$ \\
\hline 18 & $\mathrm{CMC}$ and $\mathrm{PEG}$ & $\begin{array}{l}\text { Diclofenac } \\
\text { sodium }\end{array}$ & Rotary & Upwards & $\begin{array}{l}\text { Nanospider }{ }^{\circledR} \\
\text { (Elmarco Co) }\end{array}$ & Nanofibrous mats & $\begin{array}{l}\text { In vitro drug release, } \\
\text { swelling studies }\end{array}$ & Sustained release & $\begin{array}{c}\text { Kurečič et al., } \\
2019 \text { [69] }\end{array}$ \\
\hline 19 & $\begin{array}{c}\text { PVA, CS and } \\
\text { Gr }\end{array}$ & N/A & Rotary & Upwards & $\begin{array}{c}\text { Rotary linear weir } \\
\text { electrode partially } \\
\text { immersed in polymeric } \\
\text { solution }\end{array}$ & $\begin{array}{l}\text { Nanofibrous } \\
\text { membranes }\end{array}$ & $\begin{array}{l}\text { Spectroscopic and } \\
\text { thermal } \\
\text { characterisation }\end{array}$ & $\begin{array}{c}\text { Tissue } \\
\text { engineering }\end{array}$ & $\begin{array}{c}\text { Li et al., 2019a } \\
{[55]}\end{array}$ \\
\hline 20 & $\begin{array}{l}\text { PVA, AS, Gr } \\
\text { and CNTs }\end{array}$ & N/A & Rotary & Upwards & $\begin{array}{l}\text { Rotary linear weir } \\
\text { electrode partially } \\
\text { immersed in polymeric } \\
\text { solution }\end{array}$ & $\begin{array}{l}\text { Nanofibrous } \\
\text { membranes }\end{array}$ & $\begin{array}{l}\text { Spectroscopic and } \\
\text { thermal } \\
\text { characterisation }\end{array}$ & $\begin{array}{c}\text { Tissue } \\
\text { engineering }\end{array}$ & $\begin{array}{c}\text { Li et al., 2019b } \\
{[56]}\end{array}$ \\
\hline
\end{tabular}


Table 1. Cont

\begin{tabular}{|c|c|c|c|c|c|c|c|c|c|}
\hline Study & Polymer $^{1}$ & Drug/API ${ }^{2}$ & Spinneret & Direction & Technology & Presentation & Evaluation $^{3}$ & Application & Reference \\
\hline \multirow[b]{2}{*}{21} & \multirow[b]{2}{*}{ PCL } & \multirow[b]{2}{*}{ Platelets } & Rotary & Upwards & $\begin{array}{l}\text { Nanospider }{ }^{\circledR} \\
(\text { Elmarco Co) }\end{array}$ & $\begin{array}{l}\text { 2D nanofibrous } \\
\text { scaffolds }\end{array}$ & \multirow{2}{*}{$\begin{array}{l}\text { MTS assay, in vitro } \\
\text { proliferation and APL } \\
\text { activity assay }\end{array}$} & \multirow[b]{2}{*}{$\begin{array}{l}\text { Bone tissue } \\
\text { engineering }\end{array}$} & \multirow[b]{2}{*}{$\begin{array}{l}\text { Lukášová et al., } \\
2019 \text { [57] }\end{array}$} \\
\hline & & & Rotary & Sideward & $\begin{array}{l}\text { Centrifugal spinneret } \\
\text { with a reservoir filled } \\
\text { with polymeric solution }\end{array}$ & $\begin{array}{l}\text { 3D porous } \\
\text { nanofibrous } \\
\text { scaffolds }\end{array}$ & & & \\
\hline 22 & PCL & $\begin{array}{l}\text { Chlorhexidine } \\
\text { acetate }\end{array}$ & Stationary & Upwards & $\begin{array}{l}\text { Metallic rod with a } \\
\text { droplet of the } \\
\text { polymeric solution on } \\
\text { its concave top }\end{array}$ & Nanofibrous mats & $\begin{array}{l}\text { Morphology and size } \\
\text { distribution by SEM }\end{array}$ & Antimicrobial & $\begin{array}{c}\text { Manikandan et al., } \\
2019 \text { [70] }\end{array}$ \\
\hline 23 & $\begin{array}{c}\text { PEO, CS and } \\
\text { HA }\end{array}$ & N/A & Rotary & Upwards & $\begin{array}{l}\text { Nanospider }{ }^{\circledR} \\
\text { (Elmarco Co) }\end{array}$ & $\begin{array}{c}\text { Bilayer } \\
\text { nanofibrous films }\end{array}$ & $\begin{array}{c}\text { In vitro } \\
\text { biocompatibility test }\end{array}$ & $\begin{array}{c}\text { Tissue } \\
\text { engineering }\end{array}$ & $\begin{array}{l}\text { Petrova et al., } \\
2019 \text { [61] }\end{array}$ \\
\hline 24 & PEO and BSA & N/A & Rotary & Upwards & $\begin{array}{l}\text { Nanospider }{ }^{\circledR} \\
\text { (Elmarco Co) }\end{array}$ & Nanofibrous mats & $\begin{array}{l}\text { Morphology and size } \\
\text { distribution by SEM }\end{array}$ & $\begin{array}{l}\text { Drug delivery } \\
\text { systems }\end{array}$ & $\begin{array}{l}\text { Ramakrishnan } \\
\text { et al., } 2019 \text { [71] }\end{array}$ \\
\hline 25 & PCL and PVA & N/A & Rotary & Upwards & $\begin{array}{l}\text { Nanospider }{ }^{\circledR} \\
\text { (Elmarco Co) }\end{array}$ & $\begin{array}{l}\text { Double-layered } \\
\text { planar } \\
\text { nanofibrous } \\
\text { scaffolds }\end{array}$ & $\begin{array}{l}\text { In vitro adhesion and } \\
\text { proliferation test }\end{array}$ & $\begin{array}{c}\text { Wound } \\
\text { dressing/abdominal } \\
\text { adhesion } \\
\text { prevention }\end{array}$ & $\begin{array}{l}\text { Klicova et al., } \\
2020 \text { [62] }\end{array}$ \\
\hline
\end{tabular}




\subsection{NLES Technologies Using Stationary Spinnerets}

Stationary spinnerets have also been utilised in NLES for pharmaceutical and biomedical applications. The studies that utilised stationary spinnerets in NLES for biomedical and pharmaceutical applications are discussed below. The studies that have been reported in scientific literature until now are presented in Table 1.

Cengiz-Çallığlu (2014) [63] introduced NLES with a stationary spinneret and an upwards direction of ES in the biomedical and pharmaceutical field. The study aimed to produce dextran nanofibrous layers by utilising NLES for the industrial production of biomedical products. A steel rod was used as the spinneret and a droplet of dextran solution was placed on the rod electrode before the voltage source was switched on. The rod diameter was found to be critical for the number of Taylor cones generated and the productivity of the process. A diameter of $3 \mathrm{~mm}$ or less generates only one Taylor cone, but up to six Taylor cones can be generated when the rod diameter is higher than $8 \mathrm{~mm}$. In this study, the addition of an anionic surfactant was necessary for the spinning of dextran solution. After studying the effect of the concentration of the surfactant to get appropriate nanofibers, the optimised dextran solution was forwarded to a barbed roller ES device (Nanospider ${ }^{\circledR}$, Elmarco Co) for mass production. The results showed a spinning performance of $0.67 \mathrm{~g} / \mathrm{min}$ per metre and an average diameter of $162 \mathrm{~nm}$. This work proposed a novel high performance NLES method for the fabrication of dextran nanofibers that can be used for drug delivery or as scaffolds.

Holopainen et al. (2014) [64] utilised NLES with a stationary spinneret and sideways direction of ES. They developed a set-up called "needleless twisted wire electrospinning" for the fabrication of polyvinyl pyrrolidone (PVP), hydroxyapatite (HA) and bioglass nanofibers. In the developed set-up, a vertical twisted wire was used as the spinneret and the electrospun nanofibers were collected by a cylindrical collector around the wire. The polymeric solution was fed to the twisted wire from its top and followed a rotational downward flow on the surface of the wire. The results showed high production rates of $5.23 \mathrm{~g} / \mathrm{h}$ for PVP and $1.40 \mathrm{~g} / \mathrm{h}$ for HA, but for the bioglass only a rate of $0.12 \mathrm{~g} / \mathrm{h}$ was observed. The above described set-up was robust and simple but the drying of the polymeric solution on the wire surface during the process was reported. The proposed cleaning systems of rotating coils constantly refreshing the wire surface or a continuously moving closed wire with an integrated washing step to remove dried polymeric solution are discussed as possible solutions to overcome this. In conclusion, this work presented an NLES method to increase the production rate and area of nanofibrous sheets.

Daňková et al. (2015) [65] employed an NLES set-up to prepare the PCL/magnetic nanoparticles (MNP) nanofibrous composite material. The stationary spinneret was a Teflon rod-like electrode connected with a copper wire to a high-voltage source and the direction of ES was upwards. They studied the proliferation of mesenchymal stem cells (MSC) and found that due to the synergistic effect of PCL with MNPs, their cellular adhesion and proliferation were enhanced and osteogenic differentiation was supported. Therefore, they concluded that their findings were promising for the acceleration of MSC proliferation and the regeneration of hard tissues.

Lawson et al. (2016) [66] prepared nanofibers and microfibers of PCL for the first time at rates of up to $14.0 \mathrm{~g} / \mathrm{h}$ from PCL/acetic acid (AA) precursor solutions by utilising needleless alternate current ES. The spinneret was a metallic rod of $8 \mathrm{~mm}$ diameter with a concave top that served as the polymeric solution reservoir [72]. In such experimental set-ups, a collector was not necessary because of the corona wind leading the flow of the electrospun fibers [66,72]. The direction of ES was upwards. The results showed that when sodium acetate was added as an additive to improve the spinnability of the solution, beadless PCL nanofibers with diameters ranging from 150 to $2000 \mathrm{~nm}$ were obtained. They concluded that their work would aid in the technological advancement of the commercial ES of PCL-based multipurpose nanofibers and nanofibrous constructs. Furthermore, Manikandan et al. (2019) [70] fabricated antimicrobial nanofibers from PCL/chlorhexidine acetate $(\mathrm{CHX})$ precursor solutions utilising the same alternate current ES method. In their work, the morphological characteristics of the surface of 
the fibers were smooth beadless nanofibers. Although the antimicrobial activity of the nanofibers was not examined, their potential use as antimicrobial agents was mentioned.

\subsection{Outlooks}

As we write this review paper, the COVID-19 outbreak has been declared a Public Health Emergency of International Concern by the World Health Organization (WHO) and is ongoing. The COVID-19 pandemic is expected to greatly impact society and the economy, and it will most certainly change our daily lifestyle. The use of face masks with high filtration efficiency plays an important role and has become part of the everyday routine of individuals globally [73]. Polymeric nanofiber mats exhibit high-filtration efficiency since they can absorb particles with nano-range sizes, such as virus particles; however, only non-woven nanofibrous materials have proven effective in such filtration [74,75]. NLES can be utilised for the fabrication of such non-woven nanofibrous materials and since it is associated with high production rates, it can lead to the production of thousands of masks per day. Therefore, NLES is also of great interest and high potential in the fight against COVID-19.

\section{Summary and Conclusions}

Electrospinning (ES) is a simple electrohydrodynamic process and the most commonly used method in the fabrication of nanofibers by employing electrostatic forces. For pharmaceutical and biomedical applications, the liquid solutions used in the ES process are comprised of polymeric solutions, emulsions, suspensions or melts containing one or more APIs.

ES and electrospun nanofibers have been explored for their application in drug delivery science for the last two decades. Despite its simplicity and versatility, the conventional ES method exhibits some limitations. Mainly, the low production yield and the clogging of the needles used as spinnerets need to be overcome for its successful application in the pharmaceutical and biomedical field. Moreover, since the electrospun nanofibers are intended for clinical applications, it is of significant importance to ensure inter-batch homogeneity and implement high-quality control methods. Recently, a new alternative approach to conventional ES has been proposed in the attempt to overcome these limitations. This approach is needleless electrospinning (NLES).

NLES is the process of fabricating nanofibers by electrospinning a polymeric solution directly from an open liquid surface. The spinnerets utilised in NLES are divided into two groups: (i) rotating and (ii) stationary spinnerets. The present review highlighted a preference for the research of rotating spinnerets, namely the Nanospider ${ }^{\circledR}$ technology for the fabrication of nanofibers aimed at pharmaceutical and biomedical applications. The superiority of the Nanospider ${ }^{\circledR}$ technology is probably due to the fact that it is the only experimental set-up for NLES that is commercialised. However, some researchers have studied the utilisation of stationary spinnerets in NLES and recently ultrasound-enhanced electrospinning (USES) has been proposed as a novel set-up exploiting the acoustic radiation force generated for the initiation of the ES process. Moreover, the upwards direction of ES is more convenient and beneficial with NLES since the fall of polymeric droplets on the produced nanofibrous mat is prevented.

Although NLES has been studied for the last fifteen years (2004-2020) and it has been shown to offer benefits and have advantages over conventional ES, such as a higher production yield and the absence of needle-associated problems, the topic is still under investigation and in the early stages for industrial applications. NLES has proved to be a hard to control and multivariate process; therefore, controlling electrospun fiber quality and homogeneity is challenging and requires further investigation.

Author Contributions: Conceptualisation, I.P. and J.H.; writing-original draft preparation, I.P.; writing一review and editing, I.P., I.N., I.L. and J.H.; visualisation, I.P. and J.H.; supervision, I.L. and J.H.; funding acquisition, I.P. All authors have read and agreed to the published version of the manuscript.

Funding: This work was funded by the Erasmus+ Traineeship Program Student Mobility (I.P.) and the Estonian Research Council (grant number IUT34-18) (I.L. and J.H.).

Conflicts of Interest: The authors declare no conflict of interest. 


\section{References}

1. Kilpakjian, S.; Schmid, S.R. Manufacturing Engineering and Technology, SI Edition, 7th ed.; Pearson: Hong Kong, China, 2013.

2. Gugulothu, D.; Barhoum, A.; Nerella, R.; Ajmer, R.; Bechelany, M. Fabrication of Nanofibers: Electrospinning and Non-electrospinning Techniques. In Handbook of Nanofibers; Barhoum, A., Bechelany, M., Makhlouf, A.S.H., Eds.; Springer International Publishing: Cham, Swizerland, 2019; pp. 45-77. [CrossRef]

3. Williams, G.R.; Raimi-Abraham, B.T.; Luo, C.J. Nanofibres in Drug Delivery; UCL Press: London, UK, 2018.

4. Wei, L.; Liu, C.; Mao, X.; Dong, J.; Fan, W.; Zhi, C.; Qin, X.; Sun, R. Multiple-Jet Needleless Electrospinning Approach via a Linear Flume Spinneret. Polymers 2019, 11, 2052. [CrossRef] [PubMed]

5. Wang, X.; Lin, T.; Wang, X. Scaling up the production rate of nanofibers by needleless electrospinning from multiple ring. Fibers Polym. 2014, 15, 961-965. [CrossRef]

6. Feng, C.; Khulbe, K.C.; Matsuura, T. Recent progress in the preparation, characterization, and applications of nanofibers and nanofiber membranes via electrospinning/interfacial polymerization. J. Appl. Polym. Sci. 2010, 115, 756-776. [CrossRef]

7. Dai, Y.; Liu, W.; Formo, E.; Sun, Y.; Xia, Y. Ceramic nanofibers fabricated by electrospinning and their applications in catalysis, environmental science, and energy technology. Polym. Adv. Technol. 2011, 22, 326-338. [CrossRef]

8. Reneker, D.H.; Yarin, A.L.; Fong, H.; Koombhongse, S. Bending instability of electrically charged liquid jets of polymer solutions in electrospinning. J. Appl. Phy. 2000, 87, 4531. [CrossRef]

9. Neves, N.M.; Campos, R.; Pedro, A.; Cunha, J.; Macedo, F.; Reis, R.L. Patterning of polymer nanofiber meshes by electrospinning for biomedical applications. Int. J. Nanomed. 2007, 2, 433-448.

10. Huang, Z.-M.; Zhang, Y.-Z.; Kotaki, M.; Ramakrishna, S. A review on polymer nanofibers by electrospinning and their applications in nanocomposites. Compos. Sci. Technol. 2003, 63, 2223-2253. [CrossRef]

11. Chou, S.F.; Woodrow, K.A. Relationships between mechanical properties and drug release from electrospun fibers of PCL and PLGA blends. J. Mech. Behav. Biomed. Mater. 2017, 65, 724-733. [CrossRef]

12. Deitzel, J.M.; Kleinmeyer, J.; Harris, D.; Beck Tan, N.C. The effect of processing variables on the morphology of electrospun nanofibers and textiles. Polymer 2001, 42, 261-272. [CrossRef]

13. Richard-Lacroix, M.; Pellerin, C. Molecular orientation in electrospun fibers: From mats to single fibers. Macromolecules 2013, 46, 9473-9493. [CrossRef]

14. Persano, L.; Camposeo, A.; Tekmen, C.; Pisignano, D. Industrial upscaling of electrospinning and applications of polymer nanofibers: A Review. Macromol. Mater. Eng. 2013, 298, 504-520. [CrossRef]

15. Xie, J.; Jiang, J.; Davoodi, P.; Srinivasan, M.P.; Wang, C.H. Electrohydrodynamic atomization: A two-decade effort to produce and process micro-/nanoparticulate materials. Chem. Eng. Sci. 2015, 125, 32-57. [CrossRef] [PubMed]

16. Rutledge, G.C.; Fridrikh, S.V. Formation of fibers by electrospinning. Adv. Drug Del. Rev. 2007, 59, $1384-1391$. [CrossRef] [PubMed]

17. Nair, L.S.; Bhattacharyya, S.; Laurencin, C.T. Development of novel tissue engineering scaffolds via electrospinning. Expert Opin. Biol. Ther. 2004, 4, 659-668. [CrossRef] [PubMed]

18. Megelski, S.; Stephens, J.S.; Chase, D.B.; Rabolt, J.F. Micro- and Nanostructured Surface Morphology on Electrospun Polymer Fibers. Macromolecules 2002, 35, 8456-8466. [CrossRef]

19. Bhardwaj, N.; Kundu, S.C. Electrospinning: A fascinating fiber fabrication technique. Biotechnol. Adv. 2010, 28, 325-347. [CrossRef]

20. SalehHudin, H.S.; Mohamad, E.N.; Mahadi, W.N.L.; Muhammad Afifi, A. Multiple-jet electrospinning methods for nanofiber processing: A review. Mater. Manuf. Process. 2018, 33, 479-498. [CrossRef]

21. Andrady, A.L. Science and Technology of Polymer Nanofibers; John Wiley \& Sons: Hoboken, NJ, USA, 2008.

22. Kidoaki, S.; Kwon, I.K.; Matsuda, T. Structural features and mechanical properties of in situ-bonded meshes of segmented polyurethane electrospun from mixed solvents. J. Biomed. Mater. Res. Part B 2006, 76B, $219-229$. [CrossRef]

23. De Vrieze, S.; Van Camp, T.; Nelvig, A.; Hagström, B.; Westbroek, P.; De Clerck, K. The effect of temperature and humidity on electrospinning. J. Mater. Sci. 2009, 44, 1357-1362. [CrossRef]

24. Theron, S.A.; Yarin, A.L.; Zussman, E.; Kroll, E. Multiple jets in electrospinning: Experiment and modeling. Polymer 2005, 46, 2889-2899. [CrossRef] 
25. Petrík, S. Industrial Production Technology for Nanofibers. In Nanofibers-Production, Properties and Functional Applications; Lin, T., Ed.; IntechOpen: London, UK, 2011. [CrossRef]

26. Nieminen, H.J.; Laidmäe, I.; Salmi, A.; Rauhala, T.; Paulin, T.; Heinämäki, J.; Hæggström, E. Ultrasoundenhanced electrospinning. Sci. Rep. 2018, 8, 4437. [CrossRef] [PubMed]

27. Pawłowska, S.; Rinoldi, C.; Nakielski, P.; Ziai, Y.; Urbanek, O.; Li, X.; Kowalewski, T.A.; Ding, B.; Pierini, F. Ultraviolet Light-Assisted Electrospinning of Core-Shell Fully Cross-Linked P(NIPAAm-co-NIPMAAm) Hydrogel-Based Nanofibers for Thermally Induced Drug Delivery Self-Regulation. Adv. Mater. Interfaces 2020, 2000247. [CrossRef]

28. Simm, W.; Gosling, C.; Bonart, R.; Falkai, B.V. Fibre Fleece of Electrostatically Spun Fibres and Methods of Making Same. U.S. Patent 4,143,196, 6 March 1979.

29. Yarin, A.L.; Zussman, E. Upward needleless electrospinning of multiple nanofibers. Polymer 2004, 45, 2977-2980. [CrossRef]

30. Jirsak, O.; Sanetrnik, F.; Lukas, D.; Kotek, V.; Martinova, L.; Chaloupek, J. Method of Nanofibres Production from a Polymer Solution Using Electrostatic Spinning and a Device for Carrying out the Method. U.S. Patent 7,585,437, 8 September 2009.

31. Liu, Y.; He, J.-H.; Yu, J.Y. Bubble-electrospinning: A novel method for making nanofibers. J. Phys. Conf. Ser. 2008, 96, 012001. [CrossRef]

32. Wang, X.; Niu, H.; Lin, T.; Wang, X. Needleless electrospinning of nanofibers with a conical wire coil. Polym. Eng. Sci. 2009, 49, 1582-1586. [CrossRef]

33. Thoppey, N.M.; Bochinski, J.R.; Clarke, L.I.; Gorga, R.E. Unconfined fluid electrospun into high quality nanofibers from a plate edge. Polymer 2010, 51, 4928-4936. [CrossRef]

34. Tang, S.; Zeng, Y.; Wang, X. Splashing needleless electrospinning of nanofibers. Polym. Eng. Sci. 2010, 50, 2252-2257. [CrossRef]

35. Wu, D.; Huang, X.; Lai, X.; Sun, D.; Lin, L. High throughput tip-less electrospinning via a circular cylindrical electrode. J. Nanosci. Nanotechnol. 2010, 10, 4221-4226. [CrossRef]

36. Thoppey, N.M.; Bochinski, J.R.; Clarke, L.I.; Gorga, R.E. Edge electrospinning for high throughput production of quality nanofibers. Nanotechnology 2011, 22, 345301. [CrossRef]

37. Ahmad, A.; Ali, U.; Nazir, A.; Shahzad, A.; Khaliq, Z.; Qadir, M.B.; Khan, M.A.; Ali, S.; Hassan, M.A.; Abid, S.; et al. Toothed wheel needleless electrospinning: A versatile way to fabricate uniform and finer nanomembrane. J. Mater. Sci. 2019, 54, 13834-13847. [CrossRef]

38. Kara, Y.; He, H.; Molnár, K. Shear-aided high-throughput electrospinning: A needleless method with enhanced jet formation. J. Appl. Polym. Sci. 2020, 49104. [CrossRef]

39. Niu, H.; Lin, T. Fiber generators in needleless electrospinning. J. Nanomater. 2012, 2012, 725950. [CrossRef]

40. Niu, H.; Lin, T.; Wang, X. Needleless electrospinning. I. A comparison of cylinder and disk nozzles. J. Appl. Polym. Sci. 2009, 114, 3524-3530. [CrossRef]

41. Yener, F.; Jirsak, O. Comparision of needle and roller electrospinning sytem of polyvinylbutyral. J. Nanomater. 2012, 2012, 839317. [CrossRef]

42. Huang, C.; Niu, H.; Wu, J.; Ke, Q.; Mo, X.; Lin, T. Needleless Electrospinning of Polystyrene Fibers with an Oriented Surface Line Texture. J. Nanomater. 2012, 2012, 473872. [CrossRef]

43. Niu, H.; Wang, X.; Lin, T. Needleless electrospinning: Influences of fibre generator geometry. J. Text. Inst. 2012, 103, 787-794. [CrossRef]

44. Wang, X.; Niu, H.; Wang, X.; Lin, T. Needleless electrospinning of uniform nanofibers using spiral coil spinnerets. J. Nanomater. 2012, 2012, 785920. [CrossRef]

45. Hakkarainen, E.; Korkjas, A.; Laidmae, I.; Lust, A.; Semjonov, K.; Kogermann, K.; Nieminen, H.J.; Salmi, A.; Korhonen, O.; Haeggstrom, E.; et al. Comparison of traditional and ultrasound-enhanced electrospinning in fabricating nanofibrous drug delivery systems. Pharmaceutics 2019, 11, 495. [CrossRef]

46. Laidmäe, I.; Nieminen, H.; Salmi, A.; Paulin, T.; Rauhala, T.; Falck, K.; Yliruusi, J.; Heinämäki, J.; Haeggström, E.; Veski, P. Device and Method to Produce Nanofibers and Constructs Thereof. U.S. Patent 15/561,058, 15 March 2018.

47. Sirc, J.; Kubinova, S.; Hobzova, R.; Stranska, D.; Kozlik, P.; Bosakova, Z.; Marekova, D.; Holan, V.; Sykova, E.; Michalek, J. Controlled gentamicin release from multi-layered electrospun nanofibrous structures of various thicknesses. Int. J. Nanomed. 2012, 7, 5315-5325. [CrossRef] 
48. Ai-Tang, R.; Utarak, H.; Yoovidhya, T.; Intasanta, V.; Wongsasulak, S. Fabrication and antifungal activity of cellulose acetate-based fibers encapsulating natural neem seed oil. Adv. Mater. Res. 2013, 747, 166-169. [CrossRef]

49. Huang, C.; Niu, H.; Wu, C.; Ke, Q.; Mo, X.; Lin, T. Disc-electrospun cellulose acetate butyrate nanofibers show enhanced cellular growth performances. J. Biomed. Mater. Res. A 2013, 101, 115-122. [CrossRef] [PubMed]

50. Li, D.; Wu, T.; He, N.; Wang, J.; Chen, W.; He, L.; Huang, C.; Ei-Hamshary, H.A.; Al-Deyab, S.S.; Ke, Q.; et al. Three-dimensional polycaprolactone scaffold via needleless electrospinning promotes cell proliferation and infiltration. Colloids Surf. B 2014, 121, 432-443. [CrossRef] [PubMed]

51. Li, D.; Chen, W.; Sun, B.; Li, H.; Wu, T.; Ke, Q.; Huang, C.; Ei-Hamshary, H.; Al-Deyab, S.S.; Mo, X. A comparison of nanoscale and multiscale PCL/gelatin scaffolds prepared by disc-electrospinning. Colloids Surf. B 2016, 146, 632-641. [CrossRef]

52. Syrová, Z.; Mazel, T.; Chudoba, J.; Rysová, M.; Poláková, D.; Pytlík, R. Study of silica-based electrospun nanofibers as a scaffold for human bone marrow mesenchymal stem cells. In Proceedings of the NANOCON 2015-7th International Conference on Nanomaterials-Research and Application, 14-16 October 2015, Brno, Czech Republic; pp. 419-423.

53. Lu, W.; Xu, H.; Zhang, B.; Ma, M.; Guo, Y. The Preparation of Chitosan Oligosaccharide/Alginate Sodium/Gelatin Nanofibers by Spiral-Electrospinning. J. Nanosci. Nanotechnol. 2016, 16, 2360-2364. [CrossRef] [PubMed]

54. Sasithorn, N.; Martinová, L.; Horakova, J.; Mongkholrattanasit, R. Fabrication of silk fibroin nanofibres by needleless electrospinning. In Electrospinning-Material, Techniques, and Biomedical Applications; Intech: London, UK, 2016; pp. 95-113. [CrossRef]

55. Li, T.-T.; Yan, M.; Zhong, Y.; Ren, H.-T.; Lou, C.-W.; Huang, S.-Y.; Lin, J.-H. Processing and characterizations of rotary linear needleless electrospun polyvinyl alcohol(PVA)/Chitosan(CS)/Graphene(Gr) nanofibrous membranes. J. Mater. Res. Technol. 2019, 8, 5124-5132. [CrossRef]

56. Li, T.-T.; Zhong, Y.; Yan, M.; Zhou, W.; Xu, W.; Huang, S.-Y.; Sun, F.; Lou, C.-W.; Lin, J.-H. Synergistic effect and characterization of graphene/carbon nanotubes/polyvinyl alcohol/sodium alginate nanofibrous membranes formed using continuous needleless dynamic linear electrospinning. Nanomaterials 2019, 9, 714. [CrossRef]

57. Lukasova, V.; Buzgo, M.; Vocetkova, K.; Sovkova, V.; Doupnik, M.; Himawan, E.; Staffa, A.; Sedlacek, R.; Chlup, H.; Rustichelli, F.; et al. Needleless electrospun and centrifugal spun poly-epsilon-caprolactone scaffolds as a carrier for platelets in tissue engineering applications: A comparative study with hMSCs. Mater. Sci. Eng. C Mater. Biol. Appl. 2019, 97, 567-575. [CrossRef]

58. Sirc, J.; Hampejsova, Z.; Trnovska, J.; Kozlik, P.; Hrib, J.; Hobzova, R.; Zajicova, A.; Holan, V.; Bosakova, Z. Cyclosporine A loaded electrospun poly(d,l-lactic acid)/poly(ethylene glycol) nanofibers: Drug carriers utilizable in local immunosuppression. Pharm. Res. 2017, 34, 1391-1401. [CrossRef]

59. Böttjer, R.; Grothe, T.; Ehrmann, A. Functional nanofiber mats for medical and biotechnological applications. In Narrow and Smart Textiles; Springer: Cham, Swizerland, 2018; pp. 203-214. [CrossRef]

60. Kurečič, M.; Maver, T.; Virant, N.; Ojstršek, A.; Gradišnik, L.; Hribernik, S.; Kolar, M.; Maver, U.; Kleinschek, K.S. A multifunctional electrospun and dual nano-carrier biobased system for simultaneous detection of $\mathrm{pH}$ in the wound bed and controlled release of benzocaine. Cellulose 2018, 25, 7277-7297. [CrossRef]

61. Petrova, V.A.; Chernyakov, D.D.; Poshina, D.N.; Gofman, I.V.; Romanov, D.P.; Mishanin, A.I.; Golovkin, A.S.; Skorik, Y.A. Electrospun bilayer chitosan/hyaluronan material and its compatibility with mesenchymal stem cells. Materials 2019, 12, 2016. [CrossRef]

62. Klicova, M.; Klapstova, A.; Chvojka, J.; Koprivova, B.; Jencova, V.; Horakova, J. Novel double-layered planar scaffold combining electrospun PCL fibers and PVA hydrogels with high shape integrity and water stability. Mater. Lett. 2020, 263, 127281. [CrossRef]

63. Cengiz-Çallığlu, F. Dextran nanofiber production by needleless electrospinning process. e-Polymers 2014, 14, 5-13. [CrossRef]

64. Holopainen, J.; Penttinen, T.; Santala, E.; Ritala, M. Needleless electrospinning with twisted wire spinneret. Nanotechnology 2015, 26, 025301. [CrossRef] [PubMed]

65. Dankova, J.; Buzgo, M.; Vejpravova, J.; Kubickova, S.; Sovkova, V.; Vyslouzilova, L.; Mantlikova, A.; Necas, A.; Amler, E. Highly efficient mesenchymal stem cell proliferation on poly-epsilon-caprolactone nanofibers with embedded magnetic nanoparticles. Int. J. Nanomed. 2015, 10, 7307-7317. [CrossRef] 
66. Lawson, C.; Sivan, M.; Pokorny, P.; Stanishevsky, A.; Lukáš, D. Poly( $\varepsilon$-Caprolactone) Nanofibers for Biomedical Scaffolds by High-Rate Alternating Current Electrospinning. MRS Adv. 2016, 1, 1289-1294. [CrossRef]

67. Hampejsova, Z.; Batek, J.; Sirc, J.; Hobzova, R.; Bosakova, Z. Polylactide/polyethylene glycol fibrous mats for local paclitaxel delivery: Comparison of drug release into liquid medium and to HEMA-based hydrogel model. Mon. Für Chem.-Chem. Mon. 2019, 150, 1691-1696. [CrossRef]

68. Hobzova, R.; Hampejsova, Z.; Cerna, T.; Hrabeta, J.; Venclikova, K.; Jedelska, J.; Bakowsky, U.; Bosakova, Z.; Lhotka, M.; Vaculin, S.; et al. Poly(d,l-lactide)/polyethylene glycol micro/nanofiber mats as paclitaxel-eluting carriers: Preparation and characterization of fibers, in vitro drug release, antiangiogenic activity and tumor recurrence prevention. Mater. Sci. Eng. C Mater. Biol. Appl. 2019, 98, 982-993. [CrossRef]

69. Kurečič, M.; Mohan, T.; Virant, N.; Maver, U.; Stergar, J.; Gradišnik, L.; Kleinschek, K.S.; Hribernik, S. A green approach to obtain stable and hydrophilic cellulose-based electrospun nanofibrous substrates for sustained release of therapeutic molecules. RSC Adv. 2019, 9, 21288-21301. [CrossRef]

70. Manikandan, S.; Divyabharathi, M.; Tomas, K.; Pavel, P.; David, L. Production of poly ( $\varepsilon$-caprolactone) antimicrobial nanofibers by needleless alternating current electrospinning. Mater. Today Proc. 2019, 17, 1100-1104. [CrossRef]

71. Ramakrishnan, R.; Gimbun, J.; Ramakrishnan, P.; Ranganathan, B.; Reddy, S.M.M.; Shanmugam, G. Effect of solution properties and operating parameters on needleless electrospinning of poly(ethylene oxide) nanofibers loaded with bovine serum albumin. Curr. Drug Deliv. 2019, 16, 913-922. [CrossRef]

72. Pokorny, P.; Kostakova, E.; Sanetrnik, F.; Mikes, P.; Chvojka, J.; Kalous, T.; Bilek, M.; Pejchar, K.; Valtera, J.; Lukas, D. Effective AC needleless and collectorless electrospinning for yarn production. Phys. Chem. Chem. Phys. 2014, 16, 26816-26822. [CrossRef] [PubMed]

73. Molnar, K.; Meszaros, L. The role of electrospun nanofibers in the fight against the COVID-19. Express Polym. Let. 2020, 14, 605. [CrossRef]

74. Li, Y.; Yin, X.; Yu, J.; Ding, B. Electrospun nanofibers for high-performance air filtration. Compos. Commun. 2019, 15, 6-19. [CrossRef]

75. Zeytuncu, B.; Ürper, M.; Koyuncu, İ.; Tarabara, V.V. Photo-crosslinked PVA/PEI electrospun nanofiber membranes: Preparation and preliminary evaluation in virus clearance tests. Sep. Purif. Technol. 2018, 197, 432-438. [CrossRef] 